\title{
BILANGAN KROMATIK LOKASI DARI HASIL AMALGAMASI GRAF BINTANG YANG DIHUBUNGKAN OLEH SUATU GRAF LINGKARAN
}

\author{
RUVIQA PUTRI SOLEHA, DES WELYYANTI* NARWEN \\ Program Studi S1 Matematika, \\ Fakultas Matematika dan Ilmu Pengetahuan Alam, Universitas Andalas, \\ Kampus UNAND Limau Manis Padang, Indonesia. \\ email : ruviqaputri.011@gmail.com,wely@sci.unand.ac.id,narwen@sci.unand.ac.id
}

Diterima 29 November 2019 Direvisi 3 Desember 2019 Dipublikasikan 12 Januari 2020

\begin{abstract}
Abstrak. Pada penelitian ini membahas tentang penentuan bilangan kromatik lokasi dari hasil amalgamasi graf bintang yang dihubungkan oleh suatu graf lingkaran $n S_{k, m}$ dengan $k=4, m=3$ dan $n \geq 3$ adalah $\chi_{L}\left(n S_{4,3}\right)=4$ untuk $n \leq 4$ dan $\chi_{L}\left(n S_{4,3}\right)=5$ untuk $n>4$.
\end{abstract}

Kata Kunci: Bilangan kromatik lokasi, amalgamasi graf bintang, graf lingkaran

\section{Pendahuluan}

Bilangan kromatik lokasi graf pertama kali oleh Chartrand dkk (2002) [5] dengan menentukan bilangan kromatik dari beberapa kelas graf. Di antaranya, untuk graf lintasan, $P_{n}$ dengan $n \geq 3$ diperoleh $\chi_{L}\left(P_{n}\right)=3$. Untuk graf siklus, diperoleh dua hasil yaitu untuk n ganjil berlaku $\chi_{L}\left(P_{n}\right)=3$ dan untuk $n$ genap berlaku $\chi_{L}\left(C_{n}\right)=4$. Selanjutnya juga diperoleh $\chi_{L}(G)$ untuk graf multipartit lengkap dan dua graf bintang. Pada tahun 2003 Chartrand dkk. [6] menentukan bilangan kromatik lokasi untuk graf $G$ dengan orde $n$ yang memuat graf multipartit lengkap berorder $n-1$ sebagai subgraf. Pada tahun 2011, Asmiati telah menentukan bilangan kromatik amalgamasi bintang [1]. Selanjutnya, pada tahun 2018 Asmiati dkk. telah menemukan bilangan kromatik lokasi dari amalgamasi bintang yang dihubungkan oleh suatu lintasan [3]. Pada makalah ini akan ditentukan bilangan kromatik lokasi dari amalgamasi bintang yang dihubungkan oleh suatu lingkaran, dinotasikan sebagai $n S_{k, m}$, untuk $k=4, m=3$ dan $n \geq 1$.

\section{Definisi dan Terminologi Graf}

Graf $G$ adalah pasangan himpunan $(V, E)$ dengan $V$ himpunan berhingga (tidak kosong) dan $E$ terdiri dari pasangan tak terurut dari elemen-elemen $V$ ( $E$ dapat merupakan himpunan kosong). Elemen-elemen dari $V$ disebut titik dari $G$

${ }^{*}$ penulis korespondensi 
dan elemen-elemen dari $E$ disebut sisi dari $G$. Sebagai contoh, misalkan $V(G)=$ $\left\{v_{1}, v_{2}, \cdots, v_{n}\right\}$ adalah himpunan titik yang berisi $n$ titik di $G \operatorname{dan} E(G)=$ $\left\{e_{1}, e_{2}, \cdots, e_{m}\right\}$ adalah himpunan sisi yang berisi $m$ sisi di $G$. Secara umum, sisi dapat ditulis dengan $v_{i} v_{j}$ atau $v_{j} v_{i}$.

Graf Bintang $S_{m+1}$ adalah suatu graf terhubung yang mempunyai satu titik berderajat $m$ yang disebut titik pusat dan titik lainnya yaitu $m$ titk berderajat satu. Graf siklus $C_{n}$ merupakan graf terhubung yang mempunyai $n$ titik yang setiap titiknya berderajat dua.

Bilangan kromatik dari suatu graf $G$ adalah bilangan asli terkecil $k$ sedemikian sehingga $G$ mempunyai suatu pewarnaan- $k$ titik. Bilangan kromatik dari $G$ dinotasikan dengan $\chi(G)$. Misalkan $\chi(G)=k$, ini berarti titik-titik di $G$ paling kurang diwarnai dengan $k$ warna. Jika titik-titik di $G$ diwarnai dengan $k$ warna maka tidak ada titik yang bertetangga mempunyai warna yang sama.

Kelas warna pada $G$ dinotasikan dengan $B_{i}$, merupakan titik-titik berwarna $i$ dengan $1 \leq i \leq k$. Misalkan $\Pi=\left\{B_{1}, B_{2}, \cdots, B_{k}\right\}$ merupakan partisi terurut dari $V(G)$ berdasarkan suatu pewarnaan titik, maka representasi $v$ terhadap $\Pi$ disebut kode warna dari $v$ dinotasikan dengan $c_{\Pi}(v)$. Kode warna $c_{\Pi}(v)$ dari suatu titik $v \in V(G)$ didefinisikan sebagai vektor- $k$ sebagai berikut.

$$
c_{\Pi}(v)(v)=\left(d\left(v, B_{1}\right), d\left(v, B_{2}\right) \ldots, d\left(v, B_{k}\right)\right)
$$

dimana $d\left(v, B_{i}\right)=\min \left\{d(v, x) \mid x \in B_{i}\right\}$ untuk $1 \leq i \leq k$. Jika setiap titik yang berbeda di $G$ memiliki kode warna yang berbeda untuk suatu $\Pi$, maka $c$ disebut pewarnaan lokasi dari $G$. Minimum dari banyaknya warna yang digunakan pada pewarnaan lokasi dari graf $G$ disebut bilangan kromatik lokasi dari $G$ dinotasikan $\chi_{L}(G)$. Karena setiap pewarnaan lokasi juga merupakan suatu pewarnaan maka $\chi(G) \leq \chi_{L}(G)$.

Teorema 2.1. [6] Misalkan $G$ graf terhubung dan c suatu pewarnaan lokasi pada $G$. Jika $s$ dan $t$ adalah dua titik berbeda di $G$ sedemikian sehingga $d(s, u)=d(t, u)$ untuk setiap $u \in V(G) \backslash\{s, t\}$, maka $c(s) \neq c(t)$. Dalam hal kasus ini, jika $s$ dan $t$ adalah titik-titik yang tidak bertetangga di $G$ sedemikian sehingga $c(s) \neq c(t)$.

Bukti. Misalkan $c$ adalah suatu pewarnaan lokasi pada graf terhubung $G$ dan misalkan $\Pi=\left\{B_{1}, B_{2}, \cdots, B_{m}\right\}$ adalah himpunan kelas-kelas warna dari $V(G)$. Untuk titik $s, t \in V(G)$, andaikan $c(c)=c(t)$ sedemikian sehingga $s$ dan $t$ dalam kelas warna yang sama, misal $B_{i}$ dari $\Pi$. Akibatnya, $d\left(s, B_{i}\right)=d\left(t, B_{j}\right)$ untuk setiap $j \neq i, 1 \leq j \leq m$. Akibatnya, $c_{\Pi}(s)=c_{\Pi}(t)$ sehingga $c$ bukan pewarnaan lokasi. jadi $c(s) \neq c(t)$.

Akibat 2.2. [6] Misalkan $G$ adalah graf terhubung dengan satu titik yang bertetangga dengan $m$ daun, maka $\chi_{L}(G) \geq m+1$.

Bukti. Misalkan $v$ adalah suatu titik yang bertetangga dengan $m$ daun $x_{1}, x_{2}, \cdots, x_{m}$ di $G$. Berdasarkan Teorema 2.1, setiap pewarnaan lokasi di $G$ mempunyai warna berbeda untuk setiap $x_{i}, i=1,2, \cdots, m$. Karena $v$ bertetangga de- 
ngan semua $x_{i}$ maka $v$ harus mempunyai warna yang berbeda dengan semua daun $x_{i}$. Akibatnya, $\chi_{L}(G) \geq m+1$.

\section{Bilangan Kromatik Lokasi dari Hasil Amalgamasi Graf Bintang yang Dihubungkan Graf Lingkaran}

Amalgamasi graf bintang yang dinotasikan $S_{k, m}$ untuk $k, m \geq 3$ dimana $k>m$ merupakan graf yang diperoleh dari $(k-1)$ buah graf bintang $S_{m+1}$ dengan cara menyatukan sebuah daun $m$ dari setiap graf bintang $S_{m+1}$. Titik penyatuan tersebut disebut titik pusat $S_{k, m}$. Graf $n S_{k, m}$ adalah graf yang diperoleh dari $n$ kopi graf $S_{k, m}$, Setiap titik pusat graf $S_{k, m}$ akan dinotasikan dengan $x_{i}$, untuk $i=1,2 \cdots, n$. $n S_{k, m}$ dihubungkan oleh suatu graf lingkaran $C_{n}$ dengan $n$ titik, dengan menghubungkan suatu sisi untuk setiap titik pusat $x_{i}$ ke satu titik pada lingkaran, dinotasikan dengan $y_{i}$ untuk $i=1,2 \cdots, n$. Pada graf $S_{k, m}$, titik pusat setiap graf bintang $S_{m+1}$ dinotasikan $v_{i j}$ dengan $i=1,2,3, \cdots n, j=1,2, \cdots, k-1$ sedangkan daun ke- $m$ yang menempel pada titik $v_{i j}$ dinotasikan $v_{i j t}$ dengan $t=1,2$.

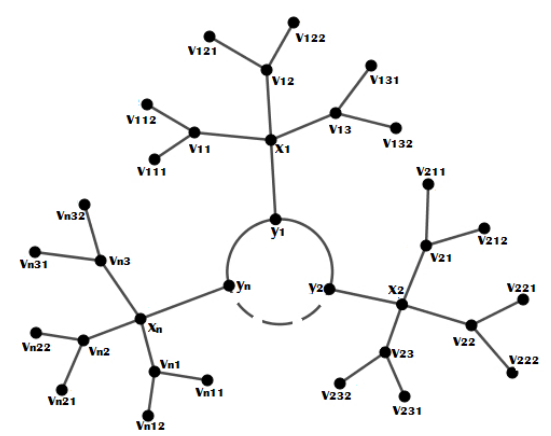

Gambar 1. Graf $n S_{k, m}$, untuk $n \geq 3, k=4$, dan $m=3$

Teorema 3.1. Misalkan terdapat amalgamasi graf bintang yang dihubungkan oleh suatu graf lingkaran, dinotasikan $n S_{4,3}$ untuk $k=4, m=3$, dan $n \geq 3$. Maka

$$
\chi_{L}\left(n S_{4,3}\right)=\left\{\begin{array}{l}
4, \text { untuk } n \leq 4 \\
5, \text { untuk } n>4
\end{array} .\right.
$$

Bukti. Kasus 1 Akan dibuktikan bahwa $\chi_{L}\left(n S_{4,3}\right)=4$ untuk $n \leq 4$.

Untuk membuktikan bahwa $\chi_{L}\left(n S_{4,3}\right)=4$ untuk $n \leq 4$, akan ditunjukkan bahwa $\chi_{L}\left(n S_{4,3}\right) \geq 4$. Berdasarkan Akibat 2.2 maka $\chi_{L}\left(n S_{4,3}\right) \geq 4$ untuk $n \leq 4$.

Selanjutnya, akan ditunjukkan bahwa $\chi_{L}\left(n S_{4,3}\right) \leq 4$. Untuk $n=3$, akan ditunjukkan $\chi_{L}\left(3 S_{4,3}\right) \leq 4$. Misalkan $c: V\left(3 S_{4,3}\right) \rightarrow\{1,2,3,4\}$, dengan

$$
\begin{aligned}
& c\left(x_{1}\right)=2, c\left(x_{2}\right)=1, c\left(x_{3}\right)=1 \\
& c\left(y_{1}\right)=1, c\left(y_{2}\right)=2, c\left(y_{3}\right)=3 \\
& c\left(v_{i j}\right) \text { untuk } i=1,2,3 \text { dan } j=1,2,3 \text { diberikan warna }\{1,2, \cdots, 4\} \backslash\left\{c\left(x_{i}\right)\right\} .
\end{aligned}
$$


$c\left(v_{i j t}\right)=\{1,2, \cdots, 4\} \backslash\left\{c\left(v_{i j}\right)\right\}$ untuk $t=1,2, i=1,2,3$ dan $j=1,2,3$.

Akibat pewarnaan $c$ akan membangun suatu partisi $\Pi=\left\{B_{1}, B_{2}, B_{3}, B_{4}\right\}$ pada $V\left(3 S_{4,3}\right)$, dengan $B_{i}$ adalah himpunan dari semua titik $i$ untuk $i=\{1,2,3,4\}$, sehingga diperoleh kelas warna sebagai berikut.

$$
\begin{aligned}
& B_{1}=\left\{y_{1}, v_{11}, v_{12}, v_{131}, x_{2}, v_{211}, v_{231}, x_{3}, v_{321}, v_{331}\right\} \\
& B_{2}=\left\{x_{1}, v_{111}, v_{132}, y_{2}, v_{21}, v_{22}, v_{311}, v_{332}, v_{331}\right\} \\
& B_{3}=\left\{v_{121}, v_{13}, v_{221}, v_{23}, y_{3}, v_{31}, v_{32}\right\} \\
& B_{4}=\left\{v_{112}, v_{122}, v_{212}, v_{222}, v_{232}, v_{312}, v_{322}, v_{33}\right\}
\end{aligned}
$$

Diperoleh pewarnaan-3 terhadap $3 S_{4,3}$, dengan $\Pi=\left\{B_{1}, B_{2}, B_{3}, B_{4}\right\}$ seperti pada Gambar 2

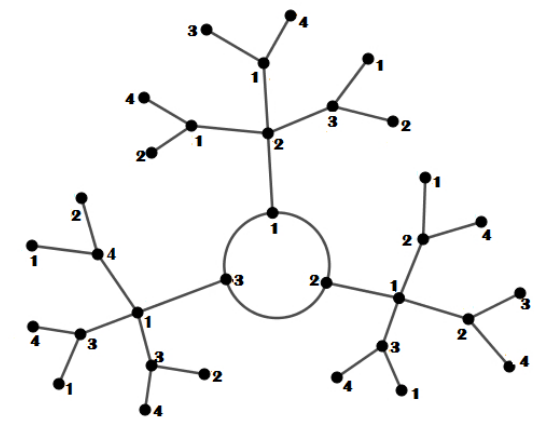

Gambar 2. Pewarnaan-3 Lokasi Graf $3 S_{4,3}$

Untuk $n=4$, akan ditunjukkan $\chi_{L}\left(4 S_{4,3}\right) \leq 4$. Misalkan $c: V\left(4 S_{4,3}\right) \rightarrow$ $\{1,2,3,4\}$, dengan

$$
\begin{aligned}
& c\left(x_{1}\right)=2, c\left(x_{2}\right)=1, c\left(x_{3}\right)=1, c\left(x_{4}\right)=1 \\
& c\left(y_{1}\right)=1, c\left(y_{2}\right)=2, c\left(y_{3}\right)=3, c\left(y_{4}\right)=4 \\
& c\left(v_{i j}\right) \text { untuk } i=1,2,3 \text { dan } j=1,2,3 \text { diberikan warna }\{1,2,3,4\} \backslash\left\{c\left(x_{i}\right)\right\} . \\
& c\left(v_{i j t}\right)=\{1,2,3,4\} \backslash\left\{c\left(v_{i j}\right)\right\} \text { untuk } t=1,2, i=1,2,3, \text { dan } j=1,2,3 .
\end{aligned}
$$

Akibat pewarnaan $c$ akan membangun suatu partisi $\Pi=\left\{B_{1}, B_{2}, B_{3}, B_{4}\right\}$ pada $V\left(4 S_{4,3}\right)$, dengan $B_{i}$ adalah himpunan dari semua titik $i$ untuk $i=\{1,2,3,4\}$, sehingga diperoleh kelas warna sebagai berikut.

$$
\begin{aligned}
& B_{1}=\left\{y_{1}, v_{11}, v_{12}, v_{13}, x_{2}, v_{211}, v_{221}, x_{3}, v_{311}, v_{321}, v_{331}, x_{4}, v_{411}, v_{421}, v_{431}\right\} \\
& B_{2}=\left\{x_{2}, v_{111}, v_{121}, y_{2}, v_{21}, v_{22}, v_{23}, v_{312}, v_{33}, v_{412}, v_{432}\right\} \\
& B_{3}=\left\{v_{112}, v_{131}, v_{212}, v_{231}, y_{3}, v_{31}, v_{32}, v_{422}, v_{43}\right\} \\
& B_{4}=\left\{v_{122}, v_{132}, v_{222}, v_{232}, v_{322}, v_{332}, y_{4}, v_{41}, v_{42}\right\}
\end{aligned}
$$

Diperoleh kode warna setiap titik di $4 S_{4,3}$ terhadap $\Pi=\left\{B_{1}, B_{2}, B_{3}, B_{4}\right\}$ seperti pada Gambar 3 


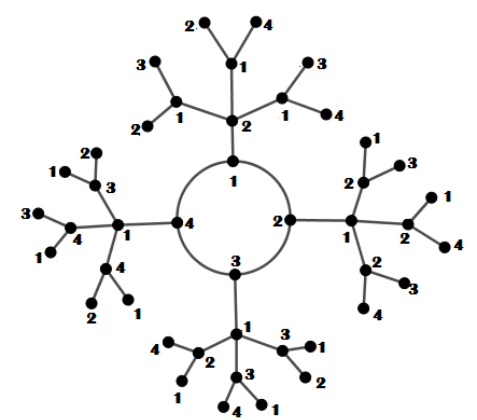

Gambar 3. Pewarnaan-4 Loakasi Graf $4 S_{4,3}$

Dari pembuktian di atas dapat dilihat bahwa $\chi_{L}\left(n S_{4,3}\right) \geq 4$ dan $\chi_{L}\left(n S_{4,3}\right) \leq 4$, sehingga dapat disimpulkan $\chi_{L}\left(n S_{k, m}\right)=4$ untuk $n \leq 4$.

Kasus 2 Akan dibuktikan bahwa $\chi_{L}\left(n S_{4,3}\right)=5$ untuk $n>4$.

Akan ditunjukkan bahwa $\chi_{L}\left(n S_{4,3}\right) \geq 5$. Berdasarkan Akibat 2.2 dan prinsip $p i$ geonhole, $\chi_{L}\left(n S_{4,3}\right) \geq 5$. Pewarnaan lokasi pada $\chi_{L}\left(n S_{4,3}\right)$ membutuhkan 5 warna. Akibatnya $\chi_{L}\left(n S_{4,3}\right) \geq 5$

Selanjutnya, akan ditunjukkan bahwa $\chi_{L}\left(n S_{4,3}\right) \geq 5$. Misalkan $c$ adalah pewarnaan dari $V\left(n S_{4,3}\right)$ dengan 5- Pewarnaan sebagai berikut.

Kasus 2.1 Untuk $C_{n}$ untuk $n$ ganjil.

$$
\begin{aligned}
& c\left(x_{i}\right)=\left\{\begin{array}{l}
1, \text { untuk } i \text { genap, } i=1,2, \cdots, n-1 \\
2, \text { untuk } i \text { ganjil, } i=1,2, \cdots, n
\end{array}\right. \\
& c\left(y_{i}\right)=\left\{\begin{array}{l}
1, \text { untuk } i \text { ganjil, } i=1,2, \cdots, n-2 \\
2, \text { untuk } i \text { genap, } i=1,2, \cdots, n-1 \\
3, \text { untuk } i=n
\end{array} .\right.
\end{aligned}
$$

Kasus 2.2 Untuk $C_{n}$ untuk $n$ genap.

$$
\begin{aligned}
& c\left(x_{i}\right)=\left\{\begin{array}{l}
1, \text { untuk } i \text { genap, } i=1,2, \cdots, n \\
2, \text { untuk } i \text { ganjil, } i=1,2, \cdots, n \backslash i=n-1
\end{array}\right. \\
& c\left(y_{i}\right)=\left\{\begin{array}{l}
1, \text { untuk } i \text { ganjil, } i=1,2, \cdots, n-3 \\
2, \text { untuk } i \text { genap, } i=1,2, \cdots, n-2 \\
3, \text { untuk } i=n-1
\end{array}\right. \\
& \begin{array}{l}
4, \text { untuk } i=n
\end{array} \\
& \left\{c\left(v_{i j}\right) \text { untuk } i=1,2,3, \cdots n \text { dan } j=1,2,3 \text { diberikan warna }\{1,2, \cdots, 4\} \backslash\right. \\
& c\left(x_{i j t}\right)=\{1,2, \cdots, 5\} \backslash\left\{c\left(v_{i j}\right)\right\} \text { untuk } t=1,2 .
\end{aligned}
$$

Akibatnya, pewarnaan $c$ akan membangun partisi $\Pi=\left\{B_{1}, B_{2}, \cdots, B_{5}\right\}$ pada $V\left(n S_{4,3}\right)$, dengan $B_{i}$ adalah himpunan dari semua titik $i$ untuk $i=1,2, \cdots, 5$. 
Akan diberikan ilustrasi untuk graf amalgamasi graf bintang seperti Gambar 4 berikut.

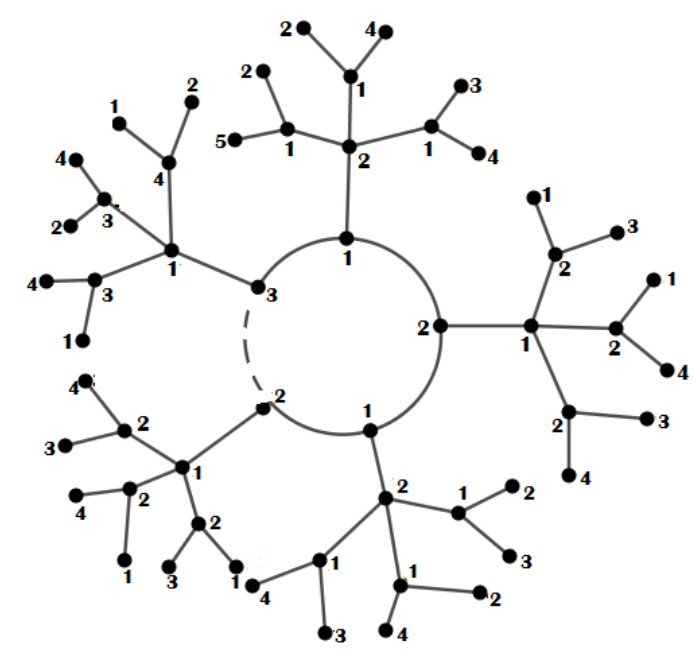

Gambar 4. Pewarnaan-n Lokasi Graf $n S_{4,3}$

Selanjutnya, akan ditunjukkan bahwa kode warna untuk setiap titik di $V\left(n S_{4,3}\right)$. Karena hanya terdapat satu daun yang berwarna 5, mengakibatkan kode warna semua titik di $V\left(n S_{4,3}\right)$ berbeda, maka $c$ merupakan pewarnaan lokasi pada $n S_{4,3}$. Jadi, $\chi_{L}\left(n S_{4,3}\right) \leq 5$ untuk $n>4$.

Dari pembuktian di atas, dapat dilihat bahwa $\chi_{L}\left(n S_{4,3}\right) \geq 5$ dan $\chi_{L}\left(n S_{4,3}\right) \leq 5$, sehingga dapat disimpulkan bahwa $\chi_{L}\left(n S_{4,3}\right)=5$ untuk $n>4$.

\section{Kesimpulan}

Pada hasil penelitian ini diperoleh bahwa bilangan kromatik lokasi dari hasil amalgamasi graf bintang yang dihubungkan oleh suatu graf lingkaran $n S_{k, m}$ dimana $k=4, m=3$, dan $n \geq 3$ adalah

$$
\chi_{L}\left(n S_{4,3}\right)=\left\{\begin{array}{l}
4, \text { untuk } n \leq 4, \\
5, \text { untuk } n>4 .
\end{array}\right.
$$

\section{Ucapan Terima kasih}

Penulis mengucapkan terima kasih kepada Ibu Lyra Yulianti, Bapak Effendi, dan Bapak Ahmad Iqbal Baqi yang telah memberikan kritik, saran, serta bimbingan sehingga penulisan makalah ini dapat diselesaikan dengan baik. 


\section{Daftar Pustaka}

[1] Asmiati and E.T. Baskoro. 2011. Locating-chromatic number of amalgamation of stars. ITB J.Sci, $43 \mathrm{~A}: 1-8$

[2] Asmiati, E.T. Baskoro, H. Assiayatun, D. Suprijanto, R.Simanjuntak and S. Uttunggadewa. 2012. Locating-chromatic number of amalgamation of Firecracker Graphs. Far East J. Math. Sci., 43(1): $11-23$

[3] Asmiati, L. Yulianti and C. Ike Tri Widyastuti. 2018. Further results on locating chromatic number for amalgamation of stars linking by one path. Indonesian Journal of Combinatorics., 2(1): 50 - 56

[4] Bondy, J.A dan Murty, U.S.R. 1976. Graph Theory with Applications. London: The Macmillan Press LTD.

[5] Carlson, K.,(2006): Generalized books and $C_{m}$-snakes are prime graphs, Ars Combinatorics, 80, 215 - 221.

[6] Chartrand, G., Erwin, D., Henning, M., Slater, P., and Zhang, P., (2002): The locating-chromatic number of a graph, Bull. Inst. Combin. Appl., 36, 89-101.

[7] Chartrand, G., Erwin, D., Henning, M., Slater, P., and Zhang, P., (2003). Graph of Order n with Locating-Chromatic Number n-1. Discrete Math. 269: 65 - 79. 